\title{
La variedad de uva País (Listán Prieto) en el Cono Sur de América: trayectoria histórica
}

\author{
Rise, Fall and Rebirth of Listán Prieto in the Southern Cone of America
}

\author{
Pablo Lacoste 1
}

\section{RESUMEN}

Este artículo estudia el itinerario histórico de la variedad de uva País (Listán Prieto) en Argentina, Chile y Perú. Se distingue su proceso de ascenso, hegemonía, declinación y resurgimiento. En cada etapa se examina la superficie cultivada, los usos (sobre todo vinos y destilados) y valoración social. Se concluye que, tras 150 años de desvalorización debido al auge del paradigma francés, la uva País ha iniciado un proceso de recuperación debido a su dimensión simbólica y su significado como patrimonio ancestral.

Palabras clave: patrimonio vitivinícola, variedades españolas de uva, Listán Prieto.

\section{ABSTRACT}

This article studies the historical itinerary of the Uva País variety (Listán Prieto) in Argentina, Chile and Peru. Its process of ascent, hegemony, decline and resurgence is distinguished. At each stage, the cultivated area, uses (especially wines and spirits) and social valuation are examined. It is concluded that, after 150 years of devaluation due to the rise of the French paradigm, the Country Grape has begun a recovery process due to its symbolic dimension and its significance as ancestral heritage. Keywords: wine heritage, Spanish-grape varieties, Listán Prieto.

\section{Introducción y revisión bibliográfica}

Listán Prieto (sinonimia: Uva País en Chile, Criolla Chica en Argentina, Negra Criolla en Perú) fue la variedad fundadora de la vitivinicultura en América. Este vidueño fue introducido tempranamente por los conquistadores españoles, y se propagó con fuerza en las zonas vitivinícolas del imperio, sobre todo en el Virreinato del Perú. A partir del siglo XVI, la Listán Prieto puso en marcha una larga historia que todavía no ha sido examinada de un modo global. La literatura especializada ha incluido esta variedad dentro de las ampelografías conosureñas (Suárez, 1911; Storni, 1929; Rojas, 1950; Vega et al., 1962; Alcalde, 2008), y la reconoce como cultivar hegemónico de los tres primeros siglos de vitivinicultura regional (Lacoste et al., 2010; Aliquo et al., 2017). Pero a partir de la imposición del paradigma francés, el centro de atención giró hacia las variedades francesas (Pszczólkowski, 2015 y 2016) dejando a la uva País en un cono de sombra, del cual solo pudo salir ocasionalmente, gracias a algunos trabajos puntuales (Lider y Lavín,
1980; Hernández et al., 1986; Sepúlveda, 1990). La uva País quedó acotada principalmente a las viñas campesinas y mantuvo su identidad asociada a los vinos y bebidas típicas tradicionales como chicha, chacolí, asoleado, pajarete y vinos de Pintatani y Codpa (Castro, 2015, 2016a y 2016b; Lacoste et al., 2015 y 2016). Sin embargo, en los últimos años se ha detectado un renovado interés por la uva País, tanto desde la perspectiva de la identidad (Aliquo et al., 2017), como por el auge del consumo de terremoto (Aguilera y Alvear, 2017) y por la revaloración de los vinos de uva País en sí mismos por su fuerte connotación patrimonial e identitaria (Mossman, 2017; Bethauer, 2017; Rojas, 2021). Más allá de estas referencias, todavía no se ha elaborado un estudio general de la evolución o "biografía" de la uva País, desde su llegada a la región hasta hoy.

\section{Materiales y métodos}

Para conocer la evolución histórica de esta variedad en los últimos 500 años se requiere

1 Universidad de Santiago de Chile. Santiago, Chile. pablo.lacoste@usach.cl 
emplear el método propio de la historia (heurísticocrítico). Ello implica examinar diversas fuentes, incluyendo testamentos, inventarios de bienes, diezmos, crónicas, memorias, relatos de viajeros y otros documentos históricos. Las fuentes cualitativas deben examinarse críticamente, con un constante trabajo de validación con datos estadísticos y marcos cronológicos. Los datos producidos en la investigación deben considerar también las fluctuaciones de cantidad de plantas o superficie cultivada con estas variedades, su régimen hídrico y forma de cultivo, junto con los cambios de valoración social. Como resultado se deben detectar los patrones para identificar los principales ciclos históricos de la trayectoria general de esta variedad.

\section{Resultados y discusión}

El análisis de la documentación disponible permite distinguir tres etapas fundamentales en la historia general de la variedad Listán Prieto en la región: apogeo, decadencia y revaloración. La etapa de apogeo se extendió desde la llegada de los españoles (mediados del siglo XVI) hasta la imposición del paradigma francés (mediados del siglo XIX). La decadencia se produjo desde esa época hasta fines del siglo XX (1850-2000) y la revaloración corresponde a los últimos veinte años (2000-2020). Cada uno de estos ciclos tuvo sus propias características y cada cambio de etapa sus causas y consecuencias. El punto crítico fue la imposición del paradigma francés, por el cual, la mayoría de los enólogos, agrónomos y empresarios vitivinícolas asumieron que la única uva capaz de entregar vinos de calidad era la obtenida de variedades francesas. La hegemonía de este paradigma fue tan abrumadora, que restó todo interés a la industria por la uva País. Los métodos de trabajo, el equipamiento y las instalaciones vitivinícolas orientadas a elaborar vinos de calidad se dedicaron casi exclusivamente a las variedades francesas. En cambio, la uva País fue relegada a un lugar secundario y elaborada sin cuidado, sin interés ni mimo. Desde el punto de vista de la construcción social del gusto, todo el esfuerzo publicitario se orientó a posicionar las variedades francesas en los lugares de calidad y prestigio, mientras que la uva País quedó invisibilizada. Los espacios de reconocimiento social de las élites, representados por el banquete de mantel largo, quedaron reservados exclusivamente a los vinos de uvas francesas, en tanto que la uva País fue relegada al espacio subalterno y popular de chinganas y ramadas. Desde el punto de vista de la jerarquía dentro de la industria vitivinícola, las empresas líderes se focalizaron exclusivamente en los cultivos de uvas francesas, mientras que los cultivos de uva País quedaron relegados a las pequeñas viñas campesinas artesanales. El Estado de Chile asumió el discurso despectivo hacia la uva País y entre 1952 y 1974 estuvo prohibida su plantación en los ricos y prósperos campos irrigados de la zona central. Como resultado, la uva País quedó confinada a las pobres tierras de secano surmaulinas (Hernández, 1986).

La superficie cultivada de uva País se redujo sustancialmente: en Argentina cayó de 41.000 a 300 hectáreas; en Chile también disminuyó y, de casi el $100 \%$ del viñedo, cayó a menos del 10\%. No se desarrollaron vinos de uva País de calidad ni de prestigio, ni en Chile ni en Argentina. Además, en Chile, la industria del pisco excluyó esta variedad de la categoría de "uvas pisqueras". Solo se mantuvo viva en Perú, donde los productores de pisco sí la conservaron como variedad selecta. La corriente principal de la enología, fuertemente influida por el paradigma francés, contribuyó al descuido y la invisibilización de la uva País. Al filo del siglo XXI se produjo una nueva etapa, signada por la revaloración de la uva País, que todavía no ha sido abordada por la academia.

\section{Fundamentos: las tres etapas históricas de la uva País}

\section{La uva País como variedad hegemónica en la región (1550-1850)}

Listán Prieto fue la variedad hegemónica en la vitivinicultura del Cono Sur de América desde la plantación de las primeras viñas, a mediados del siglo XVI, hasta el asentamiento del paradigma francés, a mediados del XIX. En esos 300 años, las viñas de Perú, Chile, Paraguay y las actuales de Bolivia y Argentina estaban formadas principalmente por plantas de Listán Prieto. Las fuentes coloniales (testamentos, cartas de dote, inventarios de bienes) mencionaban que las viñas estaban formadas por "uva negra", o "negra corriente". Por lo tanto, la inmensa mayoría de los vinos y destilados elaborados dentro de esos 
tres siglos tenían como base la uva de la variedad Listán Prieto (Tabla 1).

En los siglos XVII y XVIII, el principal polo vitivinícola de América estuvo en Perú, seguido por Chile y la actual Argentina. Los grandes espacios geoeconómicos creados por el Imperio español permitieron conectar las zonas de producción con los grandes centros de consumo, situados a grandes distancias, lo cual favoreció la expansión de la vitivinicultura. Perú tenía dos grandes polos productivos situados en Ica y Arequipa. El primero abastecía los mercados de Lima $(80.000$ habitantes) y Cusco (40.000). La intendencia de Arequipa, incluyendo los valles de Moquegua, se encargaba de surtir el vibrante mercado de Potosí (150.000 habitantes). El segundo polo vitivinícola estaba en Chile y el tercero en la actual Argentina, sobre todo en la provincia de Cuyo.

La prolongada hegemonía de la Listán Prieto en el Cono Sur permitió establecer un profundo arraigo de esta variedad en la comunidad de los campesinos viticultores. Estos aprendieron a cultivarla según las condiciones de climas y suelos de cada terroir, y desarrollaron sus saberes campesinos especializados en esta variedad. Se produjo así un fuerte vínculo entre la Listán Prieto y los campesinos del Cono Sur, el cual se mantuvo vigente en los siguientes siglos, a pesar de los cambios de las modas y las recomendaciones de los tecnócratas.

Las gestas de la Independencia marcaron la culminación de la Listán Prieto como variedad emblemática de la viticultura regional. Los dos libertadores del sur, José de San Martín y Bernardo O’Higgins, ambos viticultores, supieron apreciar las propiedades de estas variedades. Con vinos de Listán Prieto se realizaron los brindis trascendentes en la historia de la independencia del Cono Sur, además de servirse para celebrar la victoria de Chacabuco y el inicio de la continuidad del Estado de Chile (Mujica, 2019). El vino de uva País fue

Tabla 1. Polos vitivinícolas de América del Sur 1650-1850 (millones de plantas).

\begin{tabular}{lrrr}
\hline Año & Perú & Chile & Argentina \\
\hline 1650 & 12 & 7 & 0,2 \\
1750 & 20 & 15 & 4 \\
1850 & 6 & 30 & 5 \\
\hline
\end{tabular}

también el último que pudieron beber los oficiales y soldados del ejército chileno-argentino de los Andes y del cuerpo de Granaderos a Caballo de San Martín antes de la batalla de Moquegua, el 21 de enero de 1823 (Ibárcena, 2018). Esta variedad está asociada con los patriotas y la gesta de la Independencia.

\section{Auge del paradigma francés y declinación de la uva País (1850-2000)}

El asentamiento del paradigma francés marcó la declinación de la hegemonía de la Listán Prieto como variedad principal de la vitivinicultura del Cono Sur de América. A mediados del siglo XIX, la mayoría de los estadistas, políticos, enólogos, técnicos y empresarios se orientó hacia las variedades de uva francesa. Tanto en Argentina como en Chile se produjo un brusco giro hacia los vidueños que servirían para obtener vinos parecidos a los de Burdeos. Para avanzar en esa dirección, se introdujeron plantas de variedades de uva francesa. Se crearon Quintas Agronómicas y Escuelas Normales de agricultura, dedicadas a introducir cepas francesas, adaptarlas a los climas y suelos del Cono Sur, y luego, propagarlas hacia las viñas industriales y comerciales.

En medio siglo, los paisajes vitivinícolas del Cono Sur cambiaron radicalmente. Al comenzar el siglo XX, el $70 \%$ de los viñedos de Argentina estaban formados por uvas francesas, sobre todo Malbec (Suárez, 1911). Las grandes fábricas de vino, fuertemente subordinadas al paradigma francés, promovían esta variedad en sus campañas publicitarias. En el Valle Central de Chile surgieron grandes establecimientos industriales financiados por la burguesía nacional, los cuales también priorizaron las uvas francesas (Pszczólkowski, 2015; Lacoste y Pszczólkowski, 2015).

La corriente principal de la industria vitivinícola desplegó un proceso publicitario tendiente a la exaltación de las uvas francesas. El proceso de construcción del gusto y la cultura de la apreciación del vino, impulsada por la industria a través de los medios masivos de comunicación, sumía en la oscuridad las variedades hispanocriollas en general y la Listán Prieto en particular. En este periodo se produjo el cambio de nombre. Después de tres siglos de llamarse "uva negra", la Listán Prieto recibió otras denominaciones para diferenciarla de la francesa. En Chile se comenzó a llamar "Uva 
País", mientras que en Argentina fue designada como "Criolla Chica", con cierta connotación despectiva por parte de la clase dirigente formada principalmente por inmigrantes europeos, que se destacaban por su actitud minimizadora de las capas criollas a las cuales consideraban inferiores (Marianetti, 1965).

Se produjo una nueva escala de valores vitivinícola. En el tramo superior se situaron los vinos elaborados con cepas francesas, embotellados y servidos en las reuniones de las élites. Las mesas de los banquetes de mantel largo eran engalanadas con botellas de vino de estos cepajes. De ese modo, los vinos de cepas francesas se asociaban con el "alto tono humano" de los círculos exclusivos de la aristocracia. Presentar una botella de esos vinos en la mesa, era una forma de expresar el buen gusto y afirmar la pertenencia a las élites.

Si los vinos de uvas francesas estaban en la cima de la pirámide socioenológica, los caldos de Listán Prieto se colocaban en la parte más baja de la escala. Estos no tenían lugar en los banquetes. Tampoco se envasaban en botellas. Por lo general se expedían al por mayor, en pipas o bordelesas, que luego se servían en fondas, chinganas y tabernas en jarras y vasos.

La comunidad campesina mantuvo vivo el vino de uva País como parte de su cultura. Las populares fondas y ramadas se convirtieron en el espacio natural de encuentro social, alrededor de los chuicos, damajuanas y garrafas de vino, elaborado a partir de Listán Prieto. El vino de uva País era el alma de la fiesta en las chinganas y ramadas de los sectores populares. Los campesinos iban a comprarlo en chuicos, recipientes de vidrio de cinco o más litros, cuidadosamente protegidos con fibras trenzadas de mimbre de Chimbarongo. Por lo tanto, el vino tenía distintos envases, usos y significado social según su cepaje. Los vinos de uvas francesas se asociaban a la botella, al banquete y a las élites; el vino de uva País circulaba en damajuanas y se consumía en fondas y cocinerías populares rurales y urbanas.

En este periodo surgieron las nuevas fronteras enológicas en Chile. El espacio comprendido entre los ríos Aconcagua y Maule fue el reinado de la industria y el paradigma francés dedicado a elaboración de vinos, con el liderazgo de las grandes empresas como Concha y Toro, Santa Rita, Tarapacá ex Zavala, San Pedro. Estas empresas, fundadas en el último tercio del siglo XIX, constituyen hasta hoy, la punta de lanza de la vitivinicultura de Chile. Por otra parte, al norte y al sur de la zona central, los campesinos mantuvieron viva la tradición de las variedades hispanocriollas. Al sur del río Maule, los valles de Cauquenes y del Itata se destacaron por sostener sus viñas patrimoniales, con frecuencia mediante el tradicional sistema de cultivo de cabeza y con régimen hídrico de secano (sin riego), llamadas "de rulo" por los campesinos (Hernández et al., 1986). Este espacio fue la mayor reserva de viñas de Listán Prieto del Cono Sur de América.

Después de la Gran Depresión de 1930, el Estado de Chile trazó políticas activas, tendientes a regular los mercados y superar la aguda crisis que sufrió el país. En este contexto, se modelaron políticas públicas encaminadas a diferenciar las regiones productivas. La zona central quedó como cabeza de los vinos industriales de marca y el paradigma francés. En 1953, mediante una ley específica para el espacio surmaulino, se delimitó la Denominación de Origen "vino asoleado de Cauquenes y Concepción"; y para el norte, se estableció la DO "Pajarete". Ambos vinos se elaboraban a partir de variedades hispanocriollas (Castro et al., 2016; Lacoste et al., 2016).

Entre 1930 y 1973 los pequeños viticultores surmaulinos de uva País lograron sobrevivir mediante la asociación en cooperativas. El Estado tuvo cierta sensibilidad por el significado social y cultural de estos viñedos patrimoniales, y apoyó a las cooperativas mediante subsidios y respaldo técnico. Pero después de implantarse el paradigma neoliberal (1975), el papel del Estado cambió radicalmente, y se suprimieron los subsidios a las cooperativas (Sepúlveda, 1990). A partir de entonces, los campesinos dedicados a cultivar las viñas de secano quedaron abandonados a su suerte. Se quedaron sin apoyo estatal, mientras observaban el avance de las plantaciones de pinos y eucaliptus, que sí contaban con desgravámenes impositivos, subsidios y otros privilegios. Los tradicionales territorios de las cepas patrimoniales se convirtieron así en la arena de una lucha desigual, entre las grandes empresas forestales apoyadas por el Estado y las frágiles familias de viticultores artesanales, sostenidas por sus redes de solidaridad campesina.

En Argentina, la variedad Listán Prieto se encontró con otros problemas. Desde el punto de vista cuantitativo, este cultivar mantuvo su 
importancia durante un tiempo, alentado por el incremento del consumo nacional de vinos. Según las estadísticas oficiales del INV, en 1962 la superficie cultivada con esta variedad cubría una superficie de 41.470 hectáreas. De todos modos, el discurso de los tecnócratas sobre la presunta superioridad enológica de las variedades francesas comenzó, lentamente, a golpear en estas viñas patrimoniales. Este enfoque ideológico se activó cuando los problemas macroeconómicos de Argentina empezaron a hacer sentir con fuerza sus efectos en la industria del vino, particularmente por el impuesto inflacionario, problema crónico en el país en los últimos 77 años.

Desesperados por las altas tasas de inflación, los viticultores argentinos trataron de sobrevivir con un cambio drástico: reconvertir sus viñas en busca de variedades más productivas, como Criolla Grande y Cereza. A diferencia de la Listán Prieto, estas variedades carecen absolutamente de valor enológico. Con ellas es imposible elaborar buenos vinos. Sin embargo, las condiciones de mercado presionaron a los viticultores a tomar estas decisiones. Como la industria no pagaba por calidad sino por volumen de uva, los viticultores priorizaron esas variedades más productivas para elaborar vinos comunes dedicados al mercado interno masivo. En el tercer tercio del siglo XX, los viticultores argentinos arrancaron sus preciosas viñas patrimoniales de Listán Prieto. La superficie cultivada cayó de 41.000 hectáreas en 1962 a 7.700 en 1974, 3.600 en 1984, 1.800 en 1991 y 300 a comienzos del siglo XX. Se perdió así, casi totalmente, un patrimonio vitícola construido durante cuatro siglos.

Mientras tanto, en Chile, los cultivos de Listán Prieto también declinaron, pero más suavemente. Los campesinos tuvieron otros problemas: el colapso de muchas cooperativas por el repliegue del Estado; el avance de las plantaciones de pinos y eucaliptus subsidiados por los gobiernos neoliberales; el desprecio del discurso tecnocrático de enólogos, técnicos y "expertos", y la indiferencia del mercado, capturado por las grandes marcas mediante costosas campañas publicitarias.

La hegemonía del paradigma francés levantó un muro infranqueable entre los viñedos patrimoniales de uva País y los enólogos y empresarios con posibilidades de disponer de capitales necesarios para elaborar vinos cuidados. La fascinación de los vinos tipo Burdeos ocultó el valor enológico de la variedad Listán Prieto. En este periodo no se le brindó a esta uva la atención adecuada; no se la utilizó para elaborar vinos de calidad sino para vinos campesinos, como el chacolí y el pipeño (Aguilera y Alvear, 2017; Lacoste et al., 2015 y 2015b), junto con los vinos comunes para el mercado popular. En ningún caso se trabajaron estas uvas con los métodos cuidadosos propios de los vinos de calidad.

En las décadas de 1970 y 1980 se produjo un cambio significativo en el consumo de vino. Las élites entraron en una nueva etapa, de apreciación de la cultura del vino, y comenzó a crecer el consumo de vino de calidad, sobre todo de cepas francesas. En cambio, las capas populares empezaron a alejarse del vino para volcarse a la cerveza. Como resultado, cayó rápidamente el consumo de vinos comunes, lo cual afectó sensiblemente la demanda de uva País.

Las políticas públicas de Argentina y Chile coincidieron en desalentar el cultivo de uva País y promover la reconversión hacia el paradigma francés. Un estudio encargado a la Universidad de California-Davis, realizado en 1980, sobre las posibilidades de desarrollo de la vitivinicultura de Cauquenes, área donde los campesinos mantenían vivas las cepas de uva País, legitimó el pensamiento hegemónico, en el sentido de recomendar la expansión de los sistemas industriales de producción y la propagación de las cepas francesas (Líder y Lavín, 1980).

Desde su posición de poder, los tecnócratas de EE UU, avalados por los organismos técnicos de Chile, todos ellos impregnados de la ideología del paradigma francés, negaron todo valor a las cepas patrimoniales del Cono Sur, a las cuales asociaban con el atraso y la inviabilidad económica.

Un nuevo informe sobre el sector vitivinícola de secano, elaborado en 1990, sirvió para consolidar esas visiones. Las viñas patrimoniales surmaulinas, al persistir en el cultivo de uva País con métodos artesanales, carecían de posibilidades de desarrollo. De acuerdo a los tecnócratas a cargo de realizar diagnósticos y recomendaciones, coexistían entonces en Chile dos vitiviniculturas: por un lado, la industrial, con cepas nobles (francesas) y alta tecnología, situada en la zona central; por otro, la viticultura tradicional, con cepas ordinarias (uva País) y métodos artesanales, en el secano surmaulino. La primera se consideraba "eficiente" y la segunda "marginal” (Sepúlveda, 1990). 
La uva País sufrió un fuerte retroceso en Chile, entre fines del siglo XX y comienzos del XXI. La superficie cultivada con esta variedad cayó de 29.400 hectáreas en 1986 a 3.400 en 2010. Este retroceso acompañó la reducción del mercado interno, pues allí se encontraba la mayor demanda de los vinos tradicionales y patrimoniales de uva País. Predominó en esa etapa una actitud de desprecio de la uva País, pues muchos tecnócratas la estigmatizaron como variedad "sin valor enológico". La corriente principal de la industria chilena se subordinó al paradigma bordelés y de la triada de formadores de opinión industrial como Robert Parker, Robert Mondavi y Michel Roland. La industria chilena se alineó detrás del mandato de los "Puntos Parker", y con esos criterios alentó las cepas francesas y despreció la uva País.

\section{Revaloración de la uva País (2000-2020)}

En los primeros años del siglo XXI, la hegemonía del paradigma bordelés se comenzó a cuestionar desde la identidad. Algunos viticultores llamaron la atención sobre los aportes que podían significar las variedades hispanocriollas, y se empezó a valorizar el Torrontés en Argentina y la uva País en Chile. La revaloración del patrimonio vitícola ancestral del Cono Sur se produjo en el marco de un proceso mayor, signado por las corrientes mundiales de recuperación del interés por las identidades locales, como reacción a la globalización y la tendencia a la estandarización de los productos agroalimentarios. Dentro de este proceso se encuadran también otros fenómenos relevantes a nivel regional, como el ascenso de la gastronomía peruana, los productos típicos, las Denominaciones de Origen y las Indicaciones Geográficas de productos latinoamericanos, que han alcanzado un despertar notable en los últimos diez años.

En el plano vitícola, este movimiento se expresa a través de la rebelión frente al paradigma francés y los puntos Parker. Esta actitud se refleja en la revaloración de cepas autóctonas como Arenia Noir (Armenia), Assyrtiko (Grecia), Baga (Portugal), Mavrud (Bulgaria), Aglianica y Barbera (Italia). (Brethauer, 2017). En los últimos años se ha detectado un creciente interés de los enólogos por experimentar con esas variedades en busca de vinos con identidad.

Desde la perspectiva enológica, el punto de partida de la recuperación de la Listán Prieto en
Chile fue admitir el mal uso que la industria había hecho de esta variedad durante un siglo y medio. Varios observadores advirtieron que las variedades hispanocriollas eran tratadas sin mayor cuidado por parte de los enólogos y, por ello, la Listán Prieto no había entregado vinos de calidad.

Poco a poco fueron surgiendo algunos enólogos y críticos del mundo del vino, con capacidad de revalorizar la cepa País. Entre ellos se destacaron el enólogo Claudio Barria, director técnico de la Cooperativa Lomas de Cauquenes; el enólogo Felipe Zúñiga, fundador de Vid Seca y organizador de la Fiesta del Vino de Cauquenes; el wine writer Eduardo Brethauer, director de la revista bilingüe Vitis Magazine, y el comerciante canadiense Derek Mossman Knapp.

El renacimiento de la variedad País comenzó con la nueva mirada de los formadores de opinión a las viñas surmaulinas, de Cauquenes y el Itata, que se mantuvieron durante siglos con los métodos tradicionales de cultivo. Ellos comprendieron, por fin, que "esta zona es quizás la mayor reserva de plantas antiguas en el mundo, cuyo material genético subsiste desde antes, mucho antes que la plaga de la filoxera asolara los viñedos de gran parte de Europa en el siglo XIX" (Brethauer, 2017).

El descubrimiento del valor extraordinario hasta entonces oculto de la uva País convocó a algunos profesionales talentosos para abandonar su carrera en la capital, y trasladarse a vivir a la zona de viñedos patrimoniales para liderar su renacimiento. Uno de ellos fue justamente el enólogo Felipe Zúñiga. Fundamentó sus decisiones en los siguientes términos:

"La vitis vinífera no es originaria de América. Seguramente en otras regiones podemos encontrar plantas mucho más antiguas, como en Georgia o Armenia. Pero en Chile sí hemos sabido conservar un gran patrimonio de parra antiguas, pero, sobre todo, una tradición donde aún podamos con hacha y aramos el suelo a caballo. La Uva País es un cultivo endémico que se mantiene hasta nuestros días porque no hay posibilidad de reconversión. Los productores son los herederos de esta tradición y no saben hacer otra cosa. No son agricultores. ¡Son viticultores!" (Brethauer, 2017).

El renacimiento de la uva País tuvo dos polos situados en los extremos de la pirámide 
socioeconómica. Por arriba, surgieron los hípster y los enólogos innovadores. Por abajo, los consumidores populares y los jóvenes rebeldes. Estos comenzaron a revalorizar el consumo de los vinos campesinos como pipeño, chacolí y chicha. Particular ascenso logró el terremoto, convertido en trago nacional, elaborado a partir de vino pipeño (Aguilera y Alvear, 2017; Castro et al., 2016; Lacoste et al., 2015 y 2015b).

En el otro extremo del arco, se produjo también un movimiento de revalorización de la uva País desde los intelectuales y profesionales. Se comenzó entonces a innovar y experimentar con estas uvas. En poco tiempo se descubrieron resultados asombrosos. Uno de los productos con mayor éxito fue el espumante "Estelado" elaborado por Miguel Torres con uva País. Le siguieron después otros vinos reconocidos, como el espumante "Sensus" de Capel. Otras viñas comenzaron a elaborar vinos tintos de alta calidad, entre ellas Bouchon.

Paralelamente, los viticultores surmaulinos, a partir de 2015 organizaron anualmente la Fiesta del Vino País. Esta actividad se realiza en la Plaza de Armas de la ciudad de Cauquenes y se ha convertido en un referente regional. Durante tres días, los viticultores de uva País tienen la oportunidad de exhibir, difundir y vender sus vinos. En 2018 se celebró la IV edición, con participación creciente de público y expositores.

La visibilización y revaloración de la uva País fue impulsada con fuerza también por los Chanchos Deslenguados, entidad que nuclea a 22 pequeños viticultores chilenos. Esta organización se propuso organizar ferias y catas de vinos con identidad, principalmente el pipeño de uva País, marcando claras diferencias con la hegemonía de las tres grandes empresas industriales, centrada en cepas francesas. Los Chanchos Deslenguados han creado espacios para degustar vinos patrimoniales, particularmente pipeños, junto con vinos de autor, espumantes, sidras, garnachas y distintas variedades. Por lo general, estas ferias se organizan en restaurantes o patios de comidas en zonas elegantes de Santiago, como Patio Bellavista, Castillo Forestal o Borde Río (Vitacura), y logran gran éxito de convocatoria. En 2017 se celebró la XIV edición de esta propuesta, con notable aceptación.

Los vinos de uva País no están diseñados para participar en los certámenes hegemónicos de la industria del vino, signados por el predominio del paradigma francés. Tampoco se subordinan a la lógica de los Puntos Parker y a las estandarizaciones construidas a partir de una escala de valores centrada en las variedades tradicionales del mundo bordelés. Por este motivo, los especialistas en uva País recomiendan a los productores no perder tiempo, dinero ni energías en esos eventos. A diferencia de los vinos comerciales e industriales subordinados al paradigma francés, los vinos de uva País centran su fortaleza en otro punto: ellos "representan un patrimonio, son jugosos y vívidos, colmados de identidad e historia" (Brethauer, 2017). Por el contrario, lo más adecuado es afirmar la identidad y evitar, por todos los medios, subordinarse a la hegemonía del paradigma francés (Brethauer, 2017).

Desde el punto de vista comercial, los vinos patrimoniales de uva País, cultivada con los métodos artesanales, presentan una serie de fortalezas y debilidades. Uno de los problemas es la baja productividad: al no adoptar los métodos industriales y mantenerse vigentes los saberes campesinos tradicionales para cultivar la viña, estos viñedos entregan poca cantidad de uva por hectárea. Por lo general, las viñas tradicionales de rulo producen 5.500 kilogramos de uva por hectárea. Se trata de una cantidad mucho menor a la que alcanzan los viñedos industriales, que oscilan entre 20.000 y 30.000 kilogramos por hectárea. Por este motivo, esos viñedos suelen ser considerados "anticomerciales". Esta situación reina en el sistema productivo de Chile, cuyas exportaciones se valorizan a U\$S 28 por caja. Por ello, los vinos de uva País no pueden tratarse dentro del sistema general de la industria vitivinícola estandarizada. La única forma de sostener la viabilidad de estas viñas se encuentra en el desarrollo de precios superiores.

Las nuevas sensibilidades de los consumidores abrieron un nicho para el desarrollo de estos vinos. La fatiga generada por el abuso de la publicidad engañosa por parte de las grandes industrias, contribuyó a crear las condiciones para la valoración de productos artesanales en general y vinos de uva País en particular. Por ejemplo, el mundo hipster generó una corriente de demanda por este tipo de productos, lo mismo que los consumidores sensibles a la cultura y el patrimonio. Algunos comerciantes audaces detectaron estos nichos, como Derek Mossman, quien ha logrado exportar vinos chilenos de uva País a precios superiores al promedio de la industria. La botella de "País en Tinaja" elaborado 
por la viña González Bastías, del secano maulino, se vende en el mercado exterior a U\$S 27, multiplicando por seis el promedio de la botella de vino chileno de uvas francesas.

La principal fortaleza del vino de uva País se encuentra en el relato identitario que la acompaña. No se trata de copiar ni imitar el vino francés sino, al contrario, poner en valor el significado épico de los campesinos que han mantenido viva esta tradición durante 500 años. "Lo que hace única a la vitivinicultura del secano maulino y la País no es la saga de una cepa, sino la saga de un grupo humano que ha mantenido su cultura durante siglos. Son sus maneras, su forma de hablar, de comunicarse con el mundo, son sus comidas tradicionales, su vocación orgánica o sustentable, sus arados a caballo, sus podas con hacha, y a veces incluso en botes, sus zarandas y lagares, su pasión y espíritu inquebrantable, que no se rinde ante nada, que persiste más allá de lo imaginable" (Betrahuer, 2017).

Las nuevas corrientes de revalorización de la uva País han contribuido al fortalecimiento de su imagen y a incrementar la demanda del producto. Como resultado, la superficie cultivada con uva País comenzó nuevamente a crecer, hasta triplicarse entre 2010 y 2016. El renacimiento de la uva País es uno de los puntos fuertes de la vitivinicultura chilena. Entre otras fortalezas, se destaca su originalidad. El despertar de la uva País en Chile ha servido para activar esta variedad en otros países. Actualmente, la superficie cultivada de Listán Prieto en el mundo comprende 300 ha en Argentina, 200 en España, 50 en México, 50 en EE UU y 13.000 ha en Chile.

Particular interés tiene el cultivo de Listán Prieto en Perú por tratarse de una variedad patrimonial, cuya potencialidad se acentúa en articulación con las tradiciones campesinas, los paisajes culturales ancestrales y las tradiciones gastronómicas. La notable gastronomía peruana emerge como el aliado natural para desarrollar maridajes con vinos de esta variedad. A su vez, dentro de este marco general, algunos territorios pueden tener todavía mayor potencial, como el caso del valle de Moquegua, que posee viñas patrimoniales de Listán Prieto y, a la vez, una gastronomía regional de fuerte contenido identitario (Ibárcena, 2016 y 2018).

En el mundo del pisco, la variedad Listán Prieto exhibe grandes asimetrías entre Chile y Perú. En Chile, por decisión de la industria, este cultivar quedó excluido de la lista de uvas aceptadas para la elaboración del destilado, decisión perfeccionada reglamentariamente por el Servicio Agrícola Ganadero (SGA). Así se dispuso en 1994, por solicitud de la industria, para bajar los costos que causaba la costumbre de los campesinos de entregarla mezclada con otras variedades. Para lograr una pequeña ventaja financiera, la industria y el SAG no dudaron en sacrificar identidad y perjudicar a los viticultores. En cambio, en Perú, la Listán Prieto conserva un lugar central en el mundo del pisco. Entre las cuatro variedades para piscos no aromáticos, se incluyen cuatro vidueños: Uvina, Negra Criolla, Mollar y Quebranta, descendiente de la unión de las dos anteriores (Ibárcena, 2017). De este modo, la Listán Prieto llega al público cada vez que se sirve una copa de pisco sour peruana, sea en Perú, sea en los 200 restaurantes peruanos de Buenos Aires, en los 700 de Santiago de Chile o del resto del mundo.

\section{Conclusión}

La variedad Listán Prieto representa el corazón del patrimonio vitícola del Cono Sur de América. Con este cultivar se introdujo la cultura de la vid y el vino en la región. En torno a ella, los campesinos aprendieron el arte de los trabajos culturales de la viña y los secretos de la elaboración del vino. Además, desde el punto de vista social, los vinos de uva País sirvieron para construir los espacios de sociabilidad en ramadas, tabernas, fiestas y celebraciones. Paralelamente, el cultivo de esta variedad facilitó el arraigo de los grupos humanos al territorio, para levantar sus viñas y cuidar sus vinos. La geografía del Cono Sur fue significativamente modelada por comunidades campesinas dedicadas (total o parcialmente) al cultivo del viñedo y a la comercialización de sus vinos. En cierto modo, los vinos de uva País fueron un estímulo constante para la construcción de los paisajes culturales de la región.

Después de tres siglos de hegemonía, la imposición del paradigma francés marcó un largo periodo de invisibilidad de la uva País. Resulta notable el giro de la industria vitivinícola, sobre todo en Argentina y Chile. La fascinación de las variedades francesas proyectó un denso cono de sombra sobre las variedades tradicionales. La uva 
País quedó excluida de los espacios de honor y prestigio. Nadie se atrevió a valorarla ni dedicarle atención y cuidado para tratar de obtener vinos de alta calidad: de acuerdo a la ideología de la época, sólo las uvas francesas merecían esa dedicación. Detrás de este enfoque se alinearon las corrientes principales de la industria vitivinícola, la enología profesional, las campañas publicitarias y los medios influyentes de opinión. Como resultado, la uva País declinó, y la superficie cultivada se redujo considerablemente.

Los campesinos de los valles de Cauquenes y el Itata, principalmente, se resistieron a aquellas corrientes hegemónicas. Ellos se negaron a perder sus viñas patrimoniales de uva País. Mantuvieron vivas sus tradiciones, guiados más por su intuición que por las recomendaciones de los profesionales, enólogos y expertos. Movidos por una fuerza interior oculta, esos campesinos tuvieron la convicción de seguir adelante con sus cultivos de Listán Prieto. Portadores de un patrimonio ancestral, tuvieron motivos y fuerzas para mantener sus posiciones. Durante un siglo y medio, esa posición fue cuestionada y censurada por los especialistas e industriales.
El cambio de posición de las últimas décadas ha abierto un interrogante considerable sobre el papel de los campesinos. El renacimiento de la Listán Prieto tiene que ver con el nuevo ciclo de maduración de los sectores técnicos, profesionales y comerciales del Cono Sur, que han logrado superar la distorsión construida por las campañas publicitarias y el marketing agresivo de las grandes industrias, para recuperar la capacidad de descubrir y valorar los paisajes culturales y el patrimonio ancestral. Desde esta perspectiva, la Listán Prieto parece avanzar hacia una etapa de recuperación, apoyada en viticultores chilenos, pisqueros peruanos y comerciantes innovadores, junto con los wine writters divergentes y las nuevas generaciones que ya no están dispuestas a dejarse manipular por las grandes corporaciones.

\section{Agradecimiento}

El autor agradece al proyecto "Patrimonio Agroalimentario en Chile Central" No 031894LG financiado por la Dirección de Investigación Científica y Tecnológica (DICYT) de la Vicerrectoría de Investigación. Desarrollo e Innovación (VRIDEI) de la Universidad de Santiago de Chile.

\section{Literatura citada}

Aguilera, I.; Alvear, A.

2017. Pipeño y Terremoto como bebidas nacionales: una reflexión en torno a la patrimonialización y representación de la nación. RIVAR, 4 (12): 5-12.

Alcalde, A.

2008. Cultivares vitícolas argentinas. INTA. Buenos Aires, Argentina. 146 p.

Aliquo, G.; Torres, R.; Lacombe, T.; Boursiquot, J.खM.; Laucou, V.; Gualpa, J.; Fanzone, M.; Sari, S.; Perez Peña, J.; Prieto, J.A. 2017. Identity and parentage of some South American grapevine cultivars present in Argentina. Australian Journal of Grape and Wine Research, 23 (3): 452-460.

Brethauer, E.

2017. El futuro del País. Seminario Fiesta del Vino País, (1) $1-6$.

Castro, A.; Mujica, F; Argandoña, F.

2015. Entre Pintatani y Codpa. Paisaje y productos típicos en los relatos campesinos, 1847-2013. RIVAR, 2 (6): 70-86.

Castro, A.; Pszczólkowski, Ph.; Mujica, F.; Lacoste, P.; Núñez,

E.; Cofré, C.; Lacoste Adunka, M.; Soto, N.

2016. El pajarete de Huasco y Elqui (Chile). Historia de un vino escogido. Idesia, 34 (4): 85-99.

Castro, A.; León, A.; Cussen, F.; Lacoste, P.

2016. ¡Viva la chicha nueva! La chicha en la vida popular y campesina chilena. Idesia 34 (1): 77-83.
Hernández, A.; Pszczólkowski, Ph.; Morandé, P. 1986. La vid y el vino en Chile. Santiago, PUC. 146 p.

Ibárcena, J.F.

2018. Tradiciones moqueguanas. Ediciones Baluarte, 3 tomos. Moquegua, Perú. 260 p.

Lacoste, P.; Castro, A.; Rendón, B.; Pszczólkowski, P.; Soto, N.; Adunka, M.L.; Jeffs, J.; Salas, A.; Cofré, C.; Núñez, E. 2016. Asoleado de Cauquenes y Concepción: apogeo y decadencia de un vino chileno con Denominación de Origen. Idesia, 34 (1): 85-99.

Lacoste, P.; Castro, A.; Briones, F. Mujica, F. 2015. El Pipeño: historia de un vino típico del sur del Valle Central de Chile. Idesia ,33(3): 87-96.

Lacoste, P.; Castro, A., Briones, F.; Cussen, F.; Soto, N.; Rendón, B.; Mujica, F.; Aguilera, P.; Cofré, C.; Núñez, E.; Adunka, M.L. 2015b. Vinos típicos de Chile: ascenso y declinación del Chacolí (1810-2015). Idesia 33 (3): 97-108.

Lacoste, P.; Yuri, J. A.; Aranda, M.; Castro, A.; Quintero, K.; Solar, M.; Soto, N.; Gaete, J.; Rivas, J.

2010. Variedades de uva en Chile y Argentina (1550-1850): Genealogía del torrontés. Mundo Agrario, 20: 1: 1-37.

Lider, Ll.; Lavin, A.

1980. Posibilidades de desarrollo de la vitivinicultura del área de Cauquenes, VII Región del Maule. Cauquenes, INIA. $41 \mathrm{p}$. 
Marianetti, Benito.

1965. El racimo y su aventura. La cuestión vitivinícola.

Buenos Aires, Platina, Argentina. 368 p.

Mossman, D.

2017. País otra (s) perspectiva (s). Seminario Fiesta del Vino País, (2) 1-9.

Mujica, F.; Adunka L., M.; Lacoste, P.

2019. Bernardo O’Higgins y el patrimonio del vino en Chile. Idesia (Arica), 37(4):109-114.

Pszczólkowski, Ph.

2015. Sauvignon Blanc, Cabernet-Sauvignon y Carmenère, cepas claves de la viticultura actual de Chile. RIVAR, 2(4): 1-16.

Pszczólkowski, Ph.

2016. La Côt o Malbec en Chile y Argentina. RIVAR, 3 (7): 58-80.

Rojas, M.

1950. Viticultura y vinificación. $5^{\circ}$ edición. Santiago, Chile. 831 p.
Sánchez, S.

2019. El saber histórico como recurso argumentativo en las etiquetas de vino. RIVAR, 6 (16): 49-64.

Sepúlveda Navarrete, R.

1990. Sector vitivinícola de secano. Estudio de diagnóstico. Análisis y Recomendaciones. Santiago, Chile, 27 p.

Storni, C.

1927. Descripción de vidueños que se cultivan en Argentina desde la época colonial. Córdoba, Argentina. 64 p.

Suárez, L.

1911. Contribución a los estudios ampelográficos en la provincia de Mendoza. Mendoza, Imprenta y Librería González, $230 \mathrm{p}$.

Vega, J.; Alcalde, A.; Cinta, W.

1962. Variedades de vid que se cultivan en Cuyo. INTA. Buenos Aires, Argentina. 